\title{
North Pacific's Very Wide Warm Poleward Surface Flow in Summer
}

\author{
Kern E. Kenyon \\ 4632 North Lane, Del Mar, USA
}

Correspondence to: Kern E. Kenyon, kernken@aol.com

Keywords: North Pacific Ocean, Summer Warm Surge

Received: July 21, $2018 \quad$ Accepted: August 25, $2018 \quad$ Published: August 28, 2018

Copyright $\odot 2018$ by authors and Scientific Research Publishing Inc.

This work is licensed under the Creative Commons Attribution International License (CC BY 4.0).

http://creativecommons.org/licenses/by/4.0/

\section{(c) (1) Open Access}

\section{ABSTRACT}

Two independent SST atlases are compared for the western tropical North pacific by means of their monthly mean charts. Good agreement is found in three cases involving the $80 \mathrm{~F}$ isotherm in the ship-injection temperature atlas and the $25 \mathrm{C}$ isotherm in the BT atlas. From winter to summer the area between the equator and the particular isotherms doubles in size while the SST variation inside the areas is small. Also the average northward speed of the isotherms is the same: about $15 \mathrm{~cm} / \mathrm{sec}$. Mixed layer depth charts in the BT atlas strengthen an earlier prediction that in the spring and summer of every year excess absorbed solar radiation is advected out of the tropics toward the sub-polar regions, pushed by a downward slope to the north in sea level set up by thermal expansion in the deep and long surface layer trough described earlier. This is the main result of the paper.

\section{INTRODUCTION}

Sea surface temperatures of the western tropics in the North Pacific, beautifully displayed with isotherms in a classic world atlas, H. O. 225 [1], have a distinctive property: at all times they are the highest temperatures anywhere in that ocean, but they are basically no higher in summer than in winter. From this observation comes a proposal. There must exist a very efficient heat balance mechanism operating in the surface layer which keeps pace with the increased absorption of solar radiation in the summer. It has been suggested that the excess summer heat is advected north, away from the equator, in the surface layer every year [2]. Elements of physics that reasonably could bring about the northward advection were pointed out.

A few reasons for returning to this subject are due to an independent SST data set in a different atlas [3], allowing the above northward surface flow explanation to become stronger. Although the alternative atlas, put together by Margret Robinson, is restricted to the North Pacific, it is independent of the North Pacific part of H. O. 225 in two different ways. First, mercury thermometers were used to get the ship-injection data in the first atlas whereas BTs (bathythermographs) were employed in the other one. Mercury thermometers and BTs are not at all similar instruments for measuring temperature. Second, all 
the available ship-injection data up to the time of publication (1944) are contained in H. O. 225. On the other hand, the BT atlas, published in 1976, includes BT observations no earlier than 1942, so there is very little overlap in time between the two atlases. In addition, the BT atlas charts show temperatures at four other constant depths as well as the depths of the mixed layer, thereby adding another dimension to the information so to speak. Both atlases contain monthly mean charts for all 12 months.

\section{SST COMPARISONS}

From winter into spring and summer it was found before (from H. O. 225) that the surface area between the equator and the $80 \mathrm{~F}$ isotherm in the western tropics of the North Pacific doubled in size by swelling northward. That area inside the $80 \mathrm{~F}$ isotherm can be turned into a volume by multiplying by the constant depth of $100 \mathrm{~m}$, within which over $90 \%$ of the sun's radiation that penetrates the sea surface is absorbed. Volume just gives a little better idea of the quantity of heat involved than area does. After the northward swelling has stopped and the isotherms start returning to their winter positions, where has all that inferred heat in the surface layer gone to?

Here (Figure 1) the same result holds for the BT atlas: between April and August the area between the equator and the $25 \mathrm{C}$ isotherm doubles in the western tropics. Also for all 12 months, within the areas between the equator and the $25 \mathrm{C}$ isotherm, the surface temperature varies by no more than $4 \mathrm{C}$, which is consistent with the nearly constant temperatures found before inside the areas between the $80 \mathrm{~F}$ contour and the equator in the ship-injection atlas.

One further consistency check between the two independent atlases involves the average northward speed of the $25 \mathrm{C}$ isotherm compared to that of the $80 \mathrm{~F}$ isotherm, which was earlier estimated to be 14 $\mathrm{cm} / \mathrm{sec}$ from winter to summer. A calculation of the northward speed from Figure 1 came out between 12 and $17 \mathrm{~cm} / \mathrm{sec}$.

These independent agreements are worth documenting because it is doubtful that they could be carried out for any other ocean at the present time. Belief in both atlases is thereby increased.

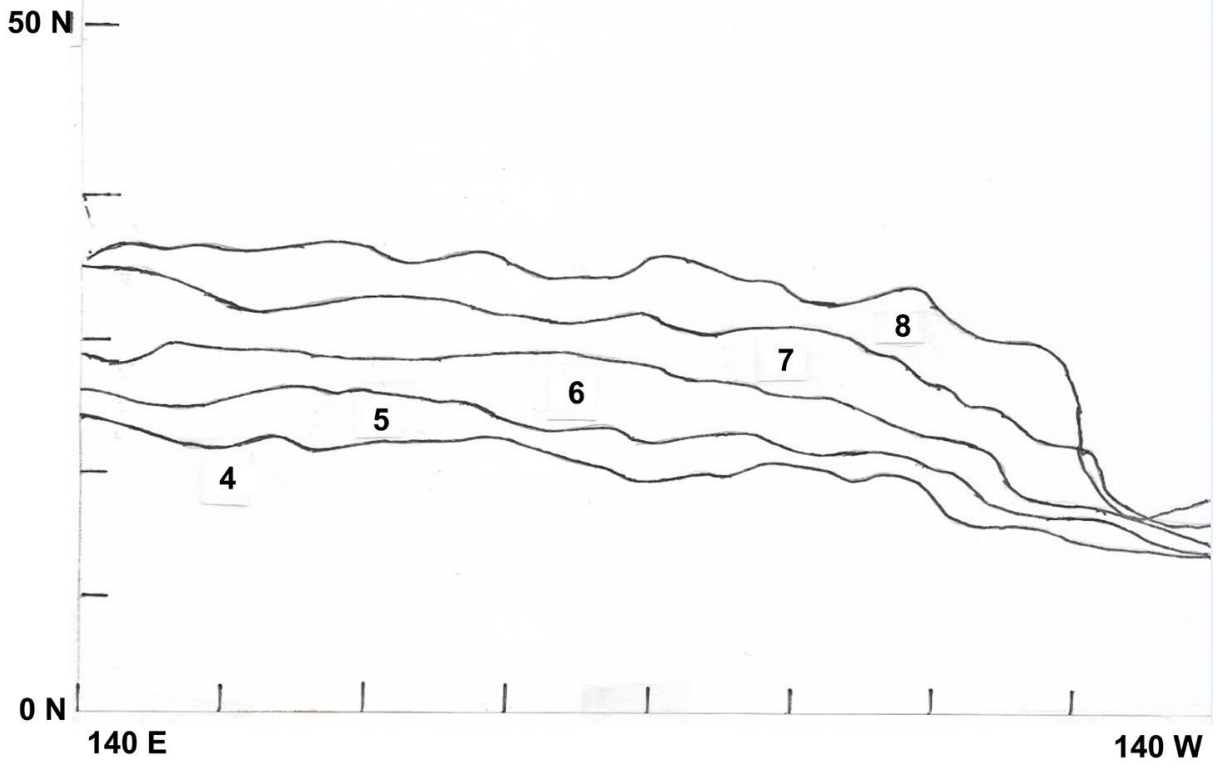

Figure 1. $25 \mathrm{C}$ isotherms as functions of latitude, longitude, and five consecutive months during the warming phase. Latitude range on the vertical axis is: $0 \mathrm{~N}$ to $50 \mathrm{~N}$, longitude range on the horizontal axis is: $140 \mathrm{E}$ to $140 \mathrm{~W}$, and the months are numbered: April = 4, etc. Traced from sea surface temperature charts in the BT atlas [3]. February and March not shown because they lie very close together and close to April as well. 


\section{MIXED LAYER DEPTH DATA}

Mixed layer depth data can be an aid to the interpretation of the sea surface temperature patterns. In the past BTs were used to measure temperature continuously as a function of depth from the surface to about $100 \mathrm{~m}$, but they are obsolete now. XBTs and STDs have replaced the BTs and they can go a lot deeper than $100 \mathrm{~m}$, and STDs measure salinity as well as temperature. Mixed layer depth charts in the BT atlas of the North Pacific stand alone at present, which means that their features cannot be independently confirmed. As far as I am aware data from XBTs and STDs have not been used in atlases yet. However, within a given monthly mean chart there is self-consistency over very large areas, and variations of characteristics from month to month are usually sensible (i.e. they don't appear to be noisy or chaotic).

Of the twelve monthly mean charts in the BT atlas showing contours of constant mixed layer depths for the whole North Pacific, two have been reproduced as illustrations in a recent paper [4]: one for the cold season (February) and the other for the warm season (July). They will be referred to again shortly.

Described in the recent paper is a large-scale continuous trough of deep mixed layer depths (at least $300 \mathrm{ft}$ ) that connects the western tropics with the Gulf of Alaska. It exists in all twelve monthly mean charts at about the same position: curving counter-clockwise, gradually initially, directed slightly north of east, and then more strongly curved nearing California. Filled with relatively warm water of nearly constant temperature, the trough is hypothesized to be constantly transporting some of the excess solar heat absorbed at and near the sea surface, mainly at lower latitudes, from the equatorial region northward toward the polar region. Where the trough crosses $35 \mathrm{~N}$ off California a complete hydrographic section measured its east-west width to be $4000 \mathrm{~km}$ and its maximum depth to be a little over $100 \mathrm{~m}$, in March and April, 1976.

As amazing as this permanent northeastward surface flow of warm water is, still it is difficult to think that it could easily adapt to summer's increased input of solar energy by enhancing the mean speed, depth or width of the flow. Some other solution to this particular aspect of the heat balance problem appears to be needed. That is where the rest of the North Pacific comes in, mainly that part north and west of the trough of deep mixed layer depths.

\section{VERY WIDE WARM NORTHWARD SURGE OF SURFACE WATER IN SUMMER}

Begin the discussion with the two BT charts recently republished. February's mixed layer depths are all greater than the BTs were able to measure (over about $400 \mathrm{ft}$ ) in a very large region of the North Pacific north of roughly $30 \mathrm{~N}$ (all white in the colored chart). Then in the July chart the same large region is covered by a shallow mixed layer depth of roughly $50 \mathrm{ft}$. Clearly a seasonal phenomenon takes place that calls for an explanation.

Transitioning from the February to the July mixed layer depth charts in the BT atlas takes place by gradual stages, or rather by small jumps that are all in the same direction. Mixed layer depths in the trough remain deep in the western tropics (at least $300 \mathrm{ft}$ ) and the trough itself stays put. North of the trough shallower and shallower mixed layers move in to the north from monthly mean to monthly mean until the whole large space is filled in with the shallowest mixed layer depth $(50 \mathrm{ft})$.

Assume that the northward migration of the $25 \mathrm{C}$ isotherm in the spring and summer (Figure 1) means that warm surface water is moving north. What causes this northward movement of water has already been speculated to be a rise in sea level due to thermal expansion in the water column at low latitudes in spring and summer. Now details of the mixed layer depth data in the BT atlas add support for such a theory. In fact the highest rise in sea level is forecast to be right along the centerline curves connecting the deepest mixed layer depths of the trough.

Where the vertical column of nearly uniformly warm water is thickest, that is where the sea level is predicted to be highest by thermal expansion. From there the sea surface slopes down toward the north. A downward sloping sea surface can drive warm surface water near the surface north. Not only is the western tropics of the North Pacific the likely origin for the permanent wide warm surface flow headed northeast off California, but it is also proposed to be the origin of the seasonal very wide warm northward surge 
of surface water every spring and summer.

\section{DISCUSSION}

Figure 2 looks like it should require equal discussion time because of being very nearly anti-symmetric to Figure 1. However, for the present purpose it is not as interesting. The main reason is that colder water coming south usually does not show up at the surface and therefore has no direct influence on the great mass of SST data that are available. This is especially true for a very wide surge of northward flowing warm water since almost all the return flow of colder water must be underneath it. In short, the physics is not symmetric: northward moving isotherms in spring and summer are due to advection whereas southward returning isotherms in fall and winter are a consequence of cooling (heat transfer from ocean to atmosphere). That is the working hypothesis.

In conjunction with the above discourse are two assumptions that should be stated explicitly: 1) no significant heat exchange in the surface layer takes place by flow crossing the equator, and 2) in terms of length/width scales there is no other comparable poleward transport of heat within the North Pacific besides the permanent wide warm current moving northeast off California plus the summer surge of warm surface water exiting to the north out of the western tropics. However, if the deep mixed layer depth areas in the $12 \mathrm{BT}$ atlas charts are consulted, it will be seen that just off Japan there is a trough, with greatest depths at about $150 \mathrm{E}$ along $35 \mathrm{~N}$, somewhat similar looking to the one off California but with horizontal scales significantly reduced. Also in the middle of the equator there are relatively small regions of mixed layer depths in the range 300 to $400 \mathrm{ft}$ centered mostly about $170 \mathrm{~W}$. Future investigations may discover something interesting happening there, perhaps regarding cross-equatorial flow in the surface layer.

To end with a speculation is tempting, even though it may just barely have survived the review process. In the earlier description of the deep mixed layer trough [4] joining the western tropics to the Gulf of Alaska, the centerline curves connecting the deepest mixed layer depths in the monthly mean data showed that most of the time the trough appeared to stay in the same location throughout the year. But in the summer some evidence indicated that the deepest part of the trough was closer to California than at any other time, particularly in June and July. There has not been time for any verification of this idea. Nevertheless, if it turns out to be true, then the following explanation might apply.

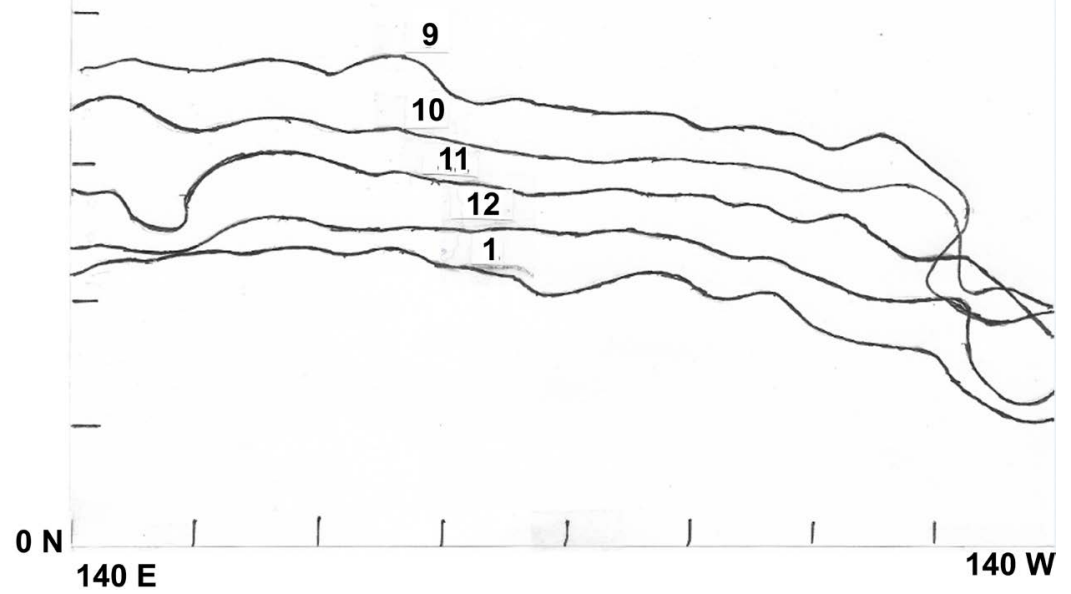

Figure 2. Same as Figure 1 except for the five consecutive months in the cooling phase. Traced from sea surface temperature charts in the BT atlas [3]. 
In the summer it is being proposed that a vast (in width) but rather thin (in depth) sheet of warm water heads north out of the western tropics for higher latitudes with speeds in the range of $10-20 \mathrm{~cm} / \mathrm{sec}$. The driving force is thought to be a sloping sea level, downward to the north, produced by thermal expansion of the warm water in the deep mixed layer trough. What the Coriolis force will try to do is to shift the flow to the east as it attempts to go north. That might result in shoving the permanent wide warm current off California closer to the continent.

At mid-latitudes (35 and $40 \mathrm{~N}$ ) the large-scale longitudinal SST maximum, which is a good signature of the northeast surface flow in that region most of the time, interferes with something going on to the west in the summers, and this was noticed as early as the 1970s. In the 20 and 30 year means the longitudinal maximum shifted significantly to the west as though it was being swamped by something larger or stronger, but only in summer. It turned out that the merging was due to the summer warm surge to the west. An open end leaves plenty of room for further investigations.

\section{CONCLUSION}

Sea surface temperatures in two independent North Pacific atlases agree that the surface area of the warm water in the western tropics expands northward during spring and summer by the same amount and at the same rate of about $15 \mathrm{~cm} / \mathrm{sec}$. With the help of monthly mean charts of mixed layer depths in the BT atlas, an earlier conjecture based on ship-injection SSTs in the other atlas is enhanced: a very wide warm surface layer moves out of the tropics to higher latitudes every year in the warm seasons. It is believed that the driving force of the northward surge is due to the sea level sloping downward to the north, which in turn is predicted to be caused by thermal expansion in the water column of the long trough of deep mixed layers in spring and summer described recently.

\section{CONFLICTS OF INTEREST}

The authors declare no conflicts of interest regarding the publication of this paper.

\section{REFERENCES}

1. (1944) World Atlas of Sea Surface Temperatures. 2nd Edition, H. O. 225, U. S. Navy, Washington DC.

2. Kenyon, K.E. (2015) Non-Seasonal SSTs of the Western Tropical North Pacific. Natural Science, 7, 605-612. https://doi.org/10.4236/ns.2015.713060

3. Robinson, M.K. (1976) Atlas of North Pacific Ocean Monthly Mean Temperatures and Mean Salinities of the Surface Layer. Department of the Navy, Washington DC.

4. Kenyon, K.E. (2018) SW Origin of North Pacific’s Wide Warm Surface Current. Natural Science, 10, No.6. 